GREEN, A. Narcisismo de vida, narcisismo de morte. São Paulo: Escuta, 1988.

HOLANDA, S. B. de. Trajetória de uma poesia. In: Cobra de vidro. São Paulo: Secretaria da Cultura, Ciência e Tecnologia/Perspectiva, 1978. p.29-44.

OLINTO, A. Nota preliminar a $O$ ritmo dissoluto. In: BANDEIRA, M. Poesia e prosa. Rio de Janeiro: José Aguilar, 1958. p.131.

PIGEAUD, J. Metáfora e melancolia: ensaios médico-filosóficos. Rio de Janeiro: PUCRio/Contraponto, 2009.

Artigo recebido em 01/08/2012 Aceito para publicação em 24/09/2012 


\title{
AS OCORRÊNCIAS DO "EU” NA POESIA DE JOÃO CABRAL
}

\section{OCCURRENCES OF "I" IN THE POETRY OF JOÃO CABRAL}

\author{
Éverton Barbosa CORREIA ${ }^{73}$
}

\begin{abstract}
RESUMO: A objetividade tem sido um elemento constante na valoração da poesia de João Cabral de Melo Neto, a despeito de a lírica ser o lugar, por excelência, da expressão subjetiva. Tendo sido tal reconhecimento poético já decantado em prosa e verso pelos seus leitores, interessaria verificar a escassa incidência do pronome pessoal do caso reto na sua produção, para que possamos dispor de um expediente linguístico concreto para apreciar a referida objetividade. Rastreando os poucos momentos em que há indicações expressivas no léxico utilizado pelo autor, a um só tempo abre-se o precedente para tecer considerações acerca de seu sujeito - que não se expressa espontaneamente - e da respectiva objetivação, que pode ser identificada quando o poeta grafa a palavra "eu".
\end{abstract}

PALAVRAS-CHAVE: Poesia Brasileira Moderna; Subjetividade; Estilo.

ABSTRACT: Objectivity has been a constant element in the valuation of the poetry of João Cabral de Melo Neto, in spite of the lyric is the place par excellence of the subjective expression. Having been such poetic recognition already decanted in prose and verse by his readers, it is interested to check the low incidence of personal pronoun in their production, so we have a concrete language to enjoy this objectivity. Tracing the few moments in which there are significant indications in the lexicon used by the author, at the same time it is opened the precedent for considerations about your subject - not expresses itself spontaneously and its objectification, that can be identified when the poet writes the word "I".

KEYWORDS: Modern Brazilian Poetry; Subjectivity; Style.

Desde quando a obra de João Cabral de Melo Neto foi acolhida pela crítica de Antonio Candido nos idos de 1942, no artigo intitulado "Poesia ao Norte" (CANDIDO, 2002, p. 135-139), a obra do pernambucano tem sido apreciada reiteradamente pelo viés da objetividade que lhe é constitutiva e que já era assinalada naquele primeiro momento. A

73 Departamento de Letras, Centro de Ciências Aplicadas e Educação, Universidade Federal da Paraíba (UFPB), CEP 58280-000, Mamanguape, PB, Brasil - evertonbcorreia@gmail.com 
informação interessa porque o Norte para o qual apontava a poesia de João Cabral naquele artigo era outro lugar, que não a região geográfica, até porque o Nordeste já estava configurado junto ao IBGE desde a década de 1930. Mesmo assim, ali reside uma percepção crítica apurada, qual seja, a de que aquela nova poesia, a despeito de suas incursões pelo universo onírico, era marcadamente objetiva. E essa marca objetiva passou a ser uma moeda de troca indiscutivelmente válida para a apreciação do poeta que não só veio a figurar em nossa Academia Brasileira de Letras, mas é reconhecido nos mais variados âmbitos e estratos sociais. Daí a compulsiva necessidade de assinalar a objetividade na obra de João Cabral que, sendo essa necessidade indiscutível, demanda descrição, demonstração e análise, já que foi tomada como uma conquista inconteste entre nossos leitores de poesia. Por isso, a pretexto de circunscrever o raio de alcance da objetividade na obra cabralina, o pronome pessoal do caso reto se nos oferece como expediente formal válido, já que se trata de um significante cuja incidência na obra de João Cabral é bastante rarefeita e nos permite, não só perceber com nitidez a transfiguração daquele sujeito em objeto, mas também reunir indícios que apontam para a subjetividade ali em curso, a considerar que o sujeito poético pode ser capturado por formas verbais, mas não só. Sendo, pois, este o primeiro horizonte de sua identificação, não tomaremos outros pronomes que poderiam apontar para o eu lírico, a exemplo dos possessivos ou dos oblíquos, porque através desses não estaríamos seguramente ataviados à dimensão subjetiva do texto, haja vista que os oblíquos e os possessivos tendem a colocar o sujeito poético na condição passiva ou reflexiva, o que não acontece quando o poeta pronuncia a palavra "eu". Outro expediente largamente utilizado pelo autor é o pronunciamento dos verbos na primeira pessoa, mas sem o sujeito, tornando-o oculto, o que também não será observado aqui, já que o que interessa é dispor de uma instância formal que explicite no espaço da página a objetividade de sua escritura e permita a especulação acerca do seu sujeito.

A este respeito, é preciso assinalar que faz pouco mais de dez anos do falecimento do autor e sua obra já apresenta problemas editoriais, cujas repercussões, a depender do ponto de vista em curso, podem interferir no seu entendimento. Refiro-me a deslocamentos de poemas - de um livro para outro - e ao aparecimento de poemas inéditos, publicados na edição da Poesia completa e prosa da Nova Aguilar de 2008, organizada por Antonio Carlos Secchin. Se tomarmos a edição anterior do mesmo volume pela mesma editora, feita 
em 1994 sob a organização de Marly de Oliveira com a colaboração do autor, que, àquela época, ainda estava vivo, perceberemos a ausência de 9 (nove) poemas - depois coligidos na edição posterior sob o epíteto de "Dispersos". Ademais, o livro Primeiros poemas publicado em 1990, viria a constar na edição de 1994 ao final do volume, ao passo que na de 2008 se apresenta como o primeiro livro constante no exemplar, o que nos permite perceber com maior acuidade o percurso desenvolvido pelo poeta. O conglomerado de informações serve para dar a dimensão de que, conforme seja a publicação do autor utilizada, sua obra muda em quantidade de poemas e versos, como também na disposição dos poemas e livros, que crescem ou diminuem de acordo com a circunstância. Por tudo isso, detive-me na edição da Nova Aguilar de 2008, organizada por Antonio Carlos Secchin, que parece ser a que melhor segue os critérios editoriais das respectivas primeiras edições de cada um dos livros. Além do mais, é preciso considerar que na edição de 1994 surge um livro a mais, já que ali houve o desdobramento do livro Sevilha Andando em outro, intitulado Andando Sevilha, que na edição original era apenas uma parte do livro anterior. Então, se considerarmos Sevilha Andando como um livro só, tal como aconteceu na edição original e na edição da Nova Aguilar de 2008, a totalidade da obra de João Cabral dispõe de 20 livros, dos quais encontramos a ocorrência da palavra "eu" em dez e dez outros sem a ocorrência do vocábulo.

Isto posto, é preciso assinalar a incidência da palavra "eu” 55 (cinquenta e cinco) vezes ao longo de toda aquela obra poética. Considerando a quantidade de versos de cada livro e o número de ocorrência da palavra "eu", por livro, podemos chegar a considerações interessantes. Pois Pedra do sono é o que tem menos versos - totalizando 295 - e um daqueles em que a ocorrência do "eu" é maior, junto com Primeiros poemas (10 ocorrências), Os três mal-amados (10 ocorrências) e $O$ rio (11 ocorrências). Ao passo que Quaderna é o tem mais versos - totalizando 1548 - e é um daqueles 10 livros de João Cabral em que não consta a palavra “eu”. Então, a primeira informação que podemos depreender do silogismo é de que há uma relação inversamente proporcional entre a quantidade de versos e a ocorrência do significante "eu". Não sendo uma relação absoluta, pois há livros em que o "eu" não aparece e tem poucos versos, como é o caso de Uma faca só lâmina, que dispõe de 353 versos e nenhuma ocorrência da palavra “eu". Porém os livros de João Cabral em que a ocorrência do “eu” é maior são justamente os de menos versos, à 
exceção de $O$ rio que tem 960 versos e onze ocorrências do vocábulo, portanto, com maior incidência do que Primeiros poemas, Pedra do sono e Os três mal-amados, que acusam a repetição dez vezes cada um e são os que têm menos versos. Mas se consideramos que no livro O rio quando o "eu” aparece está identificando com a fala do Capibaribe que se animiza e não com a do autor, o vocábulo adquire outro significado, pois está exteriorizando a fala da personagem e não da entidade que vagamente chamamos de "eu lírico". Ou melhor, o "eu lírico" naquela circunstância está filtrado ou, se assim quisermos, projetado na figura da personagem e não na do autor. Por mais que queiramos vislumbrar um intercurso entre a personagem e o autor, ainda assim, a preponderância da projeção é focada na personagem. Melhor dizendo, nas duas primeiras estrofes de $O$ rio encontramos as seguintes passagens:

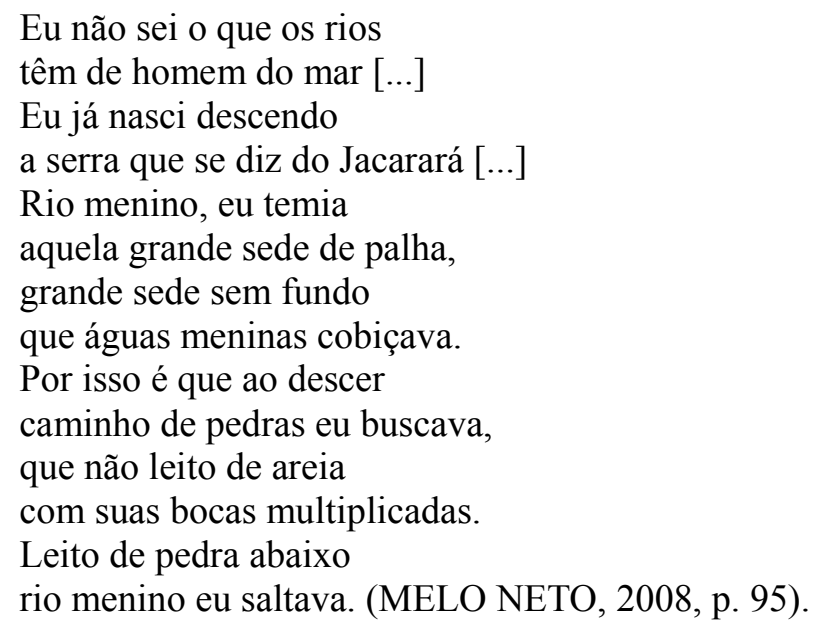

Ou seja, por mais que queiramos identificar a voz do autor tragada por essas palavras, primeiramente teremos de reconhecer que sua voz está filtrada pela transfiguração do Capibaribe em personagem, o que nos leva a crer que haja níveis de projeção de sua subjetividade, quando se divide em personagens, já que podemos identificar algo que aponta para o sujeito João Cabral de Melo Neto em sua inscrição histórica e social, enraizada no Recife e ramificada em árvores genealógicas de proprietários de terra pernambucanos à beira do Capibaribe. Sendo assim, se quisermos modalizar a ocorrência do "eu lírico" na obra de João Cabral como estando dividido entre o "eu" que é projetado em personagens e o "eu" que é projetado no autor, disporemos de 29 ocorrências projetadas nas personagens que o autor cria - a exemplo de Severino, frei Caneca, o Capibaribe ou os 
três mal-amados; e 26 outras ocorrências do "eu" que são projetados da figura do autor. Dessas 26 ocorrências projetadas da figura do autor, 10 estão nos Primeiros poemas e 10 em Pedra do sono. Ou seja, na medida em que o poeta amadurece e passa a ser reconhecido, ele deixa de usar a palavra "eu" como estando associada à sua figura, o que se torna verdadeira raridade a partir de Psicologia da composição (1947), quando o autor adquire a maioridade poética pelo reconhecimento do público leitor de poesia no alto de seus 27 anos. Depois disso, haverá apenas uma ocorrência do "eu” associada a sua figura no livro A escola das facas (1980), portanto, 43 anos e 11 livros depois. Então, para efeito de contraste, acompanharemos a leitura de dois poemas: um em que a presença do "eu" projetado da figura do autor é efusiva e outra em que é escassa e episódica; um, que está aureolado por outras ocorrências da mesma palavra e outro em que a palavra "eu" aparece perdida em meio a outras palavras; um que é da juventude do autor e outro da maturidade; um que é de Pedra do sono e outro que é de A escola das facas. Trata-se de poemas praticamente inexplorados pela crítica e, também por isso, servem melhor aos nossos propósitos. Refiro-me aos poemas "A mulher no hotel” e "Autobiografia de um só dia", coligidos respectivamente em Pedra do sono e A escola das facas. Comecemos, pois, pelo poema de juventude de João Cabral.

"A mulher no hotel"

A mulher que eu não sabia (rosas nas mãos que eu não via, olhos, braços, boca, seios), deita comigo nas nuvens. Nos seus ombros correm ventos, crescem ervas no seu leito, vejo gente no deserto onde eu sonhara morrer. Terei de engolir a poeira que seus cabelos levantam e pousa na minha alma me dando um gosto de inferno? Terei de esmagar crianças? Pisar as flores crescendo? Terei de arrasar as cidades sob seu corpo bulindo? Hei de chamar o cemitério onde um seu pé plantarei. Vou cuspir nos olhos brancos 
dessa mulher que eu não sei. (MELO NETO, 2008, p.29).

Uma primeira observação a ser feita é que as 4 (quatro) ocorrências da palavra "eu" neste poema estão mediadas por uma forte negatividade, seja quando é sucedida pelo advérbio "não" - como é o caso dos versos "A mulher que eu não sabia" "rosas nas mãos que eu não via" e "dessa mulher que eu não sei” ; seja ainda, quando a negatividade é conferida pela circunstância semântica do verso, a exemplo de "onde eu sonhara morrer". O poema chama realmente a atenção, porque jamais encontraremos outro momento da produção cabralina em que o vocábulo "eu" seja tão reincidente, mesmo se considerarmos sua produção de juventude. Este "eu" que não vê e não sabe, e não sabe no pretérito imperfeito e no presente, de tão raro se vê empalhado na produção do autor e talvez por razão semelhante tenha empanado a visão de seus leitores, que não atentaram para o poema que tem alguma graça, sendo de quem é. Sim, porque é perfeitamente possível imaginar um João Cabral que tivesse sonhado morrer - mesmo na juventude. O que há de surpreendente no poema é a efusiva ocorrência do pronome pessoal do caso reto que encandeia e ofusca a visão de seu leitor. Destaque-se também a ocorrência do ponto de interrogação, grafado quatro vezes ao longo do poema, pois raramente também encontraremos um João Cabral tão interrogativo, hesitante e indagador. Chama ainda atenção o dístico final "Vou cuspir nos olhos brancos/ dessa mulher que eu não sei”, pois um desejo tão extravagante dificilmente seria associado a seu autor, comedido e ponderado como era. O que há de perverso na manifestação do desejo torna-se mais pervertido ainda por se tratar da figura de João Cabral, cuja limpidez seus leitores se esmeraram em polir e lustrar, o que é revertido e desdobrado na sua produção de maturidade, tal como verificamos num poema de $A$ escola das facas.

"Autobiografia de um só dia"

A Maria Dulce e Luiz Tavares

No engenho Poço não nasci:

minha mãe, na véspera de mim,

veio de lá para a Jaqueira, que era de onde, queiram ou não queiram,

os netos tinham de nascer, 
no quarto-avós, frente à maré.

Ou porque chegássemos tarde

(não porque quisesse apressar-me,

e se soubesse o que queria

de tédio à frente, abortaria)

ou porque o doutor deu-me quandos,

minha mãe no quarto-dos-santos,

misto de santuário e capela,

lá dormiria, até que para ela,

fizessem cedo no outro dia

o quarto onde os netos nasciam.

Porém em pleno Céu de gesso, naquela madrugada mesmo,

nascemos eu e minha morte, contra o ritual daquela Corte

que nada de um homem sabia: que ao nascer esperneia, grita.

Parido no quarto-dos-santos, sem querer, nasci blasfemando,

pois são blasfêmias sangue e grito em meio à freirice de lírios,

mesmo se explodem (gritos, sangue), de chácara entre marés, mangues. (MELO NETO, 2008, p. 413-414).

Como o poema traz várias referências particulares ao universo do poeta, incluindo aí uma sintaxe própria, convém descrever o enredo narrado, para passarmos a outros níveis de análise com maior segurança. O episódio pode, então, ser resumido assim: os pais do poeta, Luiz Antonio Cabral de Mello e Carmem Carneiro Leão Cabral de Mello residiam no Engenho Poço (herdado do avô paterno do poeta, seu homônimo), onde um dos ramos da família Cabral de Mello teve forte ascendência. Acontece que seu avô materno Virgínio Marques Carneiro Leão exigia que todos os seus netos nascessem não só na sua casa, mas no seu próprio quarto. Daí a composição da palavra "quarto-avós" constante no poema. Esta casa era situada numa chácara de propriedade de seu avô materno, cujo nome era a 
Jaqueira, que dá nome atualmente a um bairro no Recife, já que o sítio não existe mais. $\mathrm{O}$ verso "veio de lá para a Jaqueira" informa, portanto, que sua mãe saiu do Engenho Poço onde morava - para a casa do pai dela na cidade do Recife.

Aí chegando, a gestante foi alocada no quarto dos santos, já que - a considerar a previsão do médico - o nascimento só se daria posteriormente. Diante da previsão, a futura mãe poderia circunstancialmente ficar no quarto de reza do casarão da Jaqueira, para que, no dia seguinte, começassem os preparativos com vistas à sua acomodação no quarto designado à parturiente, onde os seus filhos deveriam nascer, conforme as instâncias de seu pai. Ocorreu que, contrariando a previsão médica, naquela madrugada mesmo nasceu o rebento em hora e local imprevistos, soando gritos deslocados que ecoavam na maré do Capibaribe, onde estava plantada a casa de Virgínio Marques Carneiro Leão.

O episódio, ao que parece, repercutiu consideravelmente no seio familiar, haja vista que os irmãos mais novos do poeta não nasceram mais na casa do avô materno e que o acontecimento se converteu em capítulo importante da narrativa familiar, já que não tendo sido testemunha ocular do ocorrido, o poeta só pode ter travado conhecimento com o episódio através de oitiva que, ainda hoje, pode ser rememorada pelo seu irmão caçula e importante historiador que é Evaldo Cabral de Mello. Tendo, involuntariamente, rompido com o costume familiar de uma família tradicional pernambucana, o poeta se opõe a ela quando diz: "Nascemos eu e minha morte/ contra o ritual daquela Corte". Interessa destacar aí que toda família tradicional reivindica para si alguma nobreza, ao que podemos reputar a capacidade de figurar nalguma corte. E embora o poeta tivesse antepassados que figuraram na corte de D. Pedro II, notadamente pela linhagem dos Souza Leão, que se entronca com a dos Cabral de Mello, por um lado, e com a dos Carneiro Leão, por outra, não havia mais a necessidade de celebrar tal nobreza, já que sua existência soava algo remoto, do século anterior e que, por conseguinte, já não repercutia vivamente naqueles anos da década de 1920. Tal nobilitação familiar fica ainda mais controvertida na medida em que também é possível identificar uma nobreza vinculada ao chão pernambucano e que, além de ser simbólica, não é portadora de títulos honoríficos, na medida em que sua nobilitação é decorrente dos feitos que demarcam e consagram a história pernambucana. Ou seja, sendo simbólica esta nobreza - seja por não existir mais ou por nunca ter existido de fato -, muito mais simbólica haverá de ser a sua corte, com os seus respectivos ritos. Não havendo 
concretamente a corte, o ritual soa como o cacoete de uma nobreza que já não existia mais, ao menos no sentido nobiliárquico da nobreza. Mas o mais curioso do dístico é que antes de nomear de maneira trânsfuga sua família como uma corte de rituais perdidos, o poeta afirma que aí nasceram ele e sua morte, como se estivessem os dois de mãos dadas, já naquele momento.

Ora, o nascimento é, como sabe toda gente, um evento único e singular circunstanciado no tempo e, portanto, muito distinto e distante da morte, a não ser nos casos de natimorto, que não é o do poeta, obviamente. Sendo assim, como podem estar justapostos e imbricados o nascimento do poeta e sua morte, que se tratou de um evento a ser celebrado quase oitenta anos depois? Podemos aventar a possibilidade um tanto mistificadora de que o evento de nascimento de um sujeito já traz consigo o seu correspondente último, que seria o seu falecimento. Ocorre que este não é um procedimento usual no contexto da produção do autor e estamos, evidentemente, diante de um poema muito elaborado, portador de uma série de dísticos que também se pautam pela elaboração, em menor escala. Reconhecendo que a elaboração também existe neste dístico, a tirar pelo que os substantivos "ritual" e "corte" nos evocaram, convém especular mais um pouco sobre a relação possível entre o nascimento do poeta e sua morte, que conjugam eventos distanciados no tempo e João Cabral é um poeta para o qual a referência é importante e sempre conta.

No contexto do poema, quando o poeta grafa "minha morte" só pode estar se referindo a uma dimensão simbólica da morte, já que sua materialidade não ocorreria naquele instante. Porém no momento de seu nascimento já estava anunciado tudo aquilo contra o que o poeta teria que se insurgir durante toda sua vida e que ali já estavam inscritos nos objetos a seu redor, que representavam sua negação mais lídima e vívida na atmosfera que o circundava e que estava às margens do Capibaribe. Rio que no dialeto da família era chamado de "a maré", tal como informa o verso do poema "Prosas da maré da Jaqueira", também publicado no $A$ escola das facas, e que é atualizado neste poema aqui. Entre o curso do rio que margeava a casa de seu avô materno e o ritual inscrito no interior da vida familiar, alguma mediação precisava ser feita para a constituição do sujeito que precisava viver entre esses dois mundos: o de fora (o rio) e de dentro da casa (o universo familiar). A morte passa, então, pelo cosmo familiar que desata num mesmo cordão uma série de ritos, 
dentre os quais os religiosos, que se traduzem nos objetos mais circunstantes, que, ao mesmo tempo em que permitem uma ligação do sujeito com o seu derredor, lança-o na condição mais natural e crua, onde podemos identificar o sangue e o grito de suas blasfêmias que se opunham à freirice de lírios, constantes no penúltimo dístico: "pois são blasfêmias sangue e grito/em meio à freirice de lírios".

Se há neste momento do poema uma catolicização da natureza, na medida em que os lírios se assemelham a freiras ou à imagem que elas (as freiras) nos irradiam, é preciso dizer que, antes disso, o poeta havia engessado o céu, a pretexto de circunstanciar o ambiente de seu nascimento, quando diz: "Porém em pleno Céu de gesso,/ naquela madrugada mesmo,/ nascemos eu e minha morte, contra o ritual daquela Corte”. Do par de dístico, destaca-se o fato de que as únicas palavras grafadas em maiúsculas são "Céu” e "Corte". Sendo qualificada pela locução adjetiva "de gesso", a palavra "Céu” perde toda a magnitude indicada pelo uso da maiúscula, ao passo que a palavra "Corte" referindo-se a uma corte que não existe de fato, também contradiz a pompa que supostamente teria uma corte, o que também pode ser lido ironicamente, pelo uso da maiúscula em sentido deslocado, tal como acontece com "Céu”. Assim justapostas, as duas palavras ganham em evidenciação para esvaziar o significado do referente a que remetem, seja através de um céu engessado ou de uma corte depauperada por um ritual deslocado e perdido no tempo. Se o ritual da corte era o objeto de sua profanação, o céu de gesso dava a ancoragem necessária àquela situação, envolta de lírios e santos, provavelmente, também de gesso. Aliás, a associação é bem lógica: de gesso os santos, logo o céu também seria de gesso.

Das marcas que constituem o poema analisado, é preciso dizer que nem Maria Dulce nem Luiz Tavares (constantes na dedicatória) são de sua família e, portanto, devem ter sido os amigos pernambucanos que partilharam com o poeta o assunto que deu ensejo à composição poemática. Curioso, ainda, é notar que ao descrever a biografia alheia no mesmo livro A escola das facas, o poeta grafa o nome do biografado no corpo do respectivo poema - tal como fez com Natividade Saldanha - ou, mais ainda, no corpo e no título do poema - tal como acontece com Antonio de Moraes Silva e com Abreu e Lima, mas não aplica o mesmo procedimento a si próprio. Ao invés, não há nome, prenome ou sobrenome que o distinga particularmente no corpo do poema, de modo que, se não soubéssemos de quem é o texto, sua autoria poderia passar incógnita, não fossem os expedientes formais, 
facilmente associáveis à sua expressão. É preciso frisar, ainda, que neste poema, tal como em outros nos quais identificamos a presença de um "eu”, a subjetividade do autor se torna reconhecível pela forte incidência de formas pronominais que apontam para o sujeito estruturador do texto, quais sejam, o possessivo (minha) e os oblíquos (me, mim). Mais ainda, as formas verbais da primeira pessoa tal como ocorrem no primeiro verso (nasci) e no nono (soubesse) deixam o sujeito oculto, já que o pronome pessoal do caso reto não comparece em nenhum dos dois casos. Mas há aí uma silente e gradual passagem do sujeito oculto na primeira pessoa do singular para a primeira pessoa do plural, que ocorre no sétimo verso (chegássemos) para se concretizar e se materializar através do sujeito que, na primeira pessoa, compõe o plural com sua morte, tal como informa o verso 19: "Nascemos eu e minha morte". Com isso, o que se pretende enfatizar é que, apesar de as formas pronominais e o sujeito oculto (na primeira pessoa do singular ou do plural) não serem o foco do trabalho, estão em franca relação com o "eu", se quisermos apreciar a subjetividade do autor.

Levando em conta que subjetividade lírica não corresponde nunca a uma identidade nítida e estruturada, quando nos referirmos à obra de João Cabral de Melo Neto as manifestações daquele sujeito vão oscilar tanto em relação à figura de seu autor circunstanciado no tempo e no espaço, mas ainda assim variável -, quanto em relação às personagens em que o autor se projeta, haja vista que há níveis de projeção e que a sua identificação com as personagens também vai variar. Desta feita, o que quer que venhamos chamar de "eu lírico", na obra de João Cabral, está muito longe de ser uma entidade una, indivisível e equilibrada. Ao invés disso, estaremos sempre propensos a reconhecer naquela subjetividade algo que se traveste, se esfuma e se dilui no que ocasionalmente se apresenta como dado objetivo, seja uma personagem ou as circunstâncias histórico-sociais que se apresentam ao autor. Não deixa de ser curioso que tais expedientes sirvam de suporte necessário para que o autor profira a palavra “eu”. Aliás, sem tais suportes sua subjetividade parece não ter lugar, como se ele não pudesse ou não devesse se exprimir por si mesmo, a partir de sua condição de estar no mundo e precisasse prestar tributo a expedientes externos, a exemplo das já mencionadas personagens eleitas pelo autor ou por aquilo que ele quis como sua realidade circundante, que ele também recortava à sua maneira. 
A curiosidade se aguça tanto mais, quanto mais percebermos que o aparecimento do 'eu' no livro $A$ escola das facas é um evento único, embora não o seja no contexto de sua obra como um todo, já que podemos apontar algumas ocorrências do pronome pessoal associado à figura do autor nos livros anteriores à Psicologia da composição. Ou seja, após atingir certo grau de reconhecimento, coincidentemente a palavra "eu" desaparece de sua escritura e as outras formas pronominais indicativas de seu sujeito também, o que só voltaria acontecer explicitamente em momento ulterior de sua produção, quando já está incorporado ao panteão dos grandes autores da literatura brasileira e até da língua portuguesa. Acresce ainda que no momento de publicação deste poema em que o autor se mostra na condição pronominal, na primeira pessoa do singular, ele já está beirando a casa dos sessenta e, portanto, se trata de um momento de maturidade em que sua memória aflora quase compulsivamente, o que fica evidenciado no contexto do livro $A$ escola das facas como um todo, e que o poema analisado ilustra de modo bem particular. Isto posto, após a constatação de que há um sufocamento da subjetividade ao longo de sua produção, há o reaparecimento de um "eu" demissionário numa circunstância particular de sua escritura, quando a especulação do passado familiar propicia a religação com o seu universo de origem, sob o filtro da memória que o ata a certa prática ritualística, carregada de religiosidade, com a qual o autor não lida pacificamente.

Por outra, poderíamos dizer que é quando o poeta se observa como objeto de uma circunstância precisa, em que os espaços circunstantes passam a lhe caracterizar - seja o engenho do pai ou a casa do avô e seus cômodos - é que ele se permite ser visto como um sujeito. Sujeito que não é absolutamente individual, mas, ao contrário, se vê espelhado nos santos e devotos que o acompanham, no céu e no teto que o protege. É como parte de toda uma ambiência ao seu redor que aquele sujeito aparece, porque aí podemos visualizá-lo histórica e geograficamente enraizado no seio familiar, que aponta necessariamente para uma genealogia que desaparece no corpo do poema e na história, mas que lhe deu substância naquele momento, como sujeito histórico e como sujeito lírico.

Ele se apresenta, então, como parte de um ritual esdrúxulo que seria celebrado por ocasião de seu nascimento, que, quando se dá, rompe com o cerimonial que devia consignar-lhe alguma pompa, na medida em que subscreveria - mesmo sem querer - a escrita daquele rito macabro, que atualizava a árvore genealógica que o acolhia e lhe servia 
da guarida. João Cabral rompe com aquele arremedo de cerimônia, radicalizando-o, quando nasce num outro local que não o programado e antes do dia e da hora previstos. Tudo isso interessa, porque dá a dimensão do indivíduo no contexto da coletividade representada pela sua família, que não é uma família qualquer, quer tomemos qualquer um de seus costados. No momento em que o sujeito historicamente situado naquele contexto genealógico rompe com o ritual familiar, rompe em alguma medida com a sua família. E foi assim que ele quis ser visto, sem o apoio da família e sem o apoio do respectivo ritual - de teor católico -, cruamente exibido em sua condição natural, entre sangue e gritos, entre marés e mangues, tal como foi o seu nascimento que adquire valor fundante à sua autoimagem, ao menos assim é a partir do que lhe contaram e se cristalizou em poesia.

Acontece que o episódio que deu impulso à narrativa familiar que chegou até o poeta se confunde e se justapõe a outras narrativas familiares, a exemplo da que identificamos noutros poemas do mesmo livro, tais como "Antonio de Moraes Silva", "Tio e sobrinho" ou "Menino de três engenhos". Sendo que este último poema, a depender da publicação figura no livro A escola das facas - tal como consta na edição da Nova Aguilar de 1994 - ou no Crime na Calle Relator - tal como figura na publicação original e na segunda edição da Nova Aguilar de 2008. A informação serve para constatarmos que, assim como a obra do poeta se vale de fios narrativos que enredam uma narração familiar, também os seus leitores se valem de expedientes para credenciar tal ou qual leitura de sua obra, inclusive através de expedientes editoriais. Mas como estamos chegando, cada vez mais, a uma compreensão mais consequente e menos ortodoxa de sua obra, já é tempo de averiguar como tais narrativas se conjugam e se tocam, partindo, sobretudo, do que podemos identificar a partir dos próprios poemas.

Neste sentido, é mais do que oportuna a lembrança do poema "Descoberta da literatura", pois se o poema "Autobiografia de um só dia" chama outros poemas do mesmo livro que apontam para especulação semelhante do universo familiar no que ele tem de simbólico e isso serve para a demarcação do seu sujeito, sendo do mesmo livro, o poema "A descoberta da literatura" dá a dimensão de como ele se inseriu no universo literário através de uma narrativa própria, na qual o autor se transfigura a um só tempo em narrador e personagem, embora a narração seja feita na terceira pessoa, tal como constatamos na primeira parte do poema, abaixo transcrita: 
No dia-a-dia do engenho,
toda semana durante,
cochichavam-me em segredo:
saiu um novo romance.
E da feira de domingo
me traziam conspirantes
para que os lesse e explicasse
um romance de barbante.
Sentados na roda morte
de um carro de boi, sem jante,
ouviam o folheto guenzo,
a seu leitor semelhante,
com as peripécias de espanto
preditas pelos feirantes. (MELO NETO, 2008, p. 447).

A circunstância que se faz objeto da narração é a leitura de folhetos de cordel para trabalhadores de engenho de cana-de-açúcar. Acontece que o engenho era o de Luiz Antonio Cabral de Mello e o leitor era o seu filho João, que na época andava com os seus oito a dez anos. Foi assim que o autor travou contato com a literatura, em situação quase clandestina, haja vista que seu pai decerto não veria com bons olhos a relação do menino com os empregados. Se a circunstância foi capaz de fundar uma experiência que vai repercutir no autor que o menino viria a ser posteriormente, seja pela identificação com os tipos marginais - apesar de ser filho do engenho -, seja pela incorporação de uma modalidade métrica oriunda das bocas populares, ou ainda, de um vocabulário simples e direto que visava à comunicação imediata, o fato é que este poema serve de ótimo exemplo do modo como o autor fala de si mesmo, como se representa em perspectiva e como expressa sua subjetividade. Pois as palavras que identificamos no texto que nos conduzem a ele são as seguintes: o pronome oblíquo "me" que tem duas ocorrências e que o colocam na condição de objeto, tanto em "cochichavam-me" quanto em "me traziam"; o adjetivo "semelhante" que aproxima o menino do folheto, que é tão guenzo quanto ele; todos os grifos para as formas verbais no subjuntivo (lesse e explicasse), que, ainda que se reportem a um fato ocorrido, esfumam-se numa temporalidade passada imprecisa, que, por extensão, acabam por embaçar também o sujeito da ação, que fica ambiguamente diluído entre a primeira e a terceira pessoa.

Ora, sendo este o modo usual de João Cabral se expressar - e isso pode ser verificado até mesmo no livro $A$ escola das facas -, causa espécie que ele tenha utilizado a primeira 
pessoa tão abertamente no poema "Autobiografia de um só dia". Pois após a descrição da cena e do ambiente que lhe confere uma tonalidade mórbida, através da qual o poema se expande, ele grafa o "eu" no seguinte dístico: "Nascemos eu e minha morte, contra o ritual daquela Corte." E embora esta não tenha sido uma das portas de entrada mais frequentadas pela sua crítica, a morte ocupa na obra de João Cabral um papel determinante. Não só como o anúncio da "indesejada das gentes", mas no plano simbólico (SECCHIN, 1996, p. 66), principalmente, como a negação do que é dado enquanto possibilidade, cujo registro mais explícito é perceptível já no título de sua obra mais conhecida e que se desdobra em inúmeros de seus poemas, inclusive naqueles que tematizam cemitérios pernambucanos e naqueles em que membros da família estão enterrados e que ultrapassam a fronteira do estado natal.

Ao grafar no mesmo verso "eu e minha morte", o poeta justapõe no mesmo plano o que lhe é próprio e o que é a sua negação, ambas as dimensões inscritas no mesmo espaço, que recebe a si e o seu reverso, ao contrário do que supostamente se elegeria como imagem única e acabada. Em vez disso, o que temos é um espaço carcomido pelas imagens de santo, esterilizado pela beatitude de gesso ou lírios e confrontado pela maré de mangues, onde explodem gritos e sangue, que passam a ser sua afirmação (GARCIA, 1996, p. 230). Ao menos, o sangue de sua genealogia e o grito de sua dor, que agora é modalizado, se quisermos insistir no plano simbólico. Mais, o sangue aponta simultaneamente para sua carne e também para sua ancestralidade, ao passo que o grito revela apenas o desespero de uma voz cuja impostação é desafinada e talvez até vacilante, pelo contraditório que enseja.

Por ora, impõe-se a observação de que estamos lidando com um sujeito cujo olhar oscila entre o mangue para onde dá a janela do quarto de seu nascimento e a sombra dos antepassados que é dada pela sua árvore genealógica. É dessa tradição familiar que advém o culto aos santos, cuja religiosidade é inerente, sem poder evitar o nascimento dos filhos blasfemos, como é o caso. Assim, parece plausível aquela justaposição entre o sujeito e sua morte, já que a tradição católica nunca vai deixar de lhe assombrar. Em parte, pela formação escolar que teve em colégio marista (católico), mas sobretudo pela linhagem que lhe resguarda e que já estava devidamente assomada no dia de seu nascimento.

A constituição daquele sujeito se faz, pois, na conjunção do que ele apresenta como sendo próprio, seu eu, e seu reverso, sua morte. Contra o que aquela corte nada sabia da 
singularidade de um homem, que é grito e esperneio. Suas blasfêmias, aliás, são seu próprio corpo: sangue e grito. Sangue do que ele é na sua constituição de sujeito venoso e também no que ele carrega de sangue azul da nobreza da terra. Grito do que há de revolta no seu discurso, mas também de medida. Medida essa que se confunde com sua própria voz, com a singularidade do sujeito que é e que não se conforma aos espaços que lhe foram dados, sejam geográficos ou sociais. Parido no quarto-dos-santos, sua sentença de condenação perpétua é estar atrelado - ainda que contra a vontade - a um universo bem determinado, que se coloca diante dos seus olhos e não deixa de avivar o seu passado familiar, que coincide com o passado do próprio país, às vezes. Também por isso quando olha para trás não é só a casa dos avós que ele vê, mas também certa experiência, meio bizarra e meio jocosa, mas que não deixa de ter um valor histórico, simbolizado no poema pelo lugar de onde ele saiu para nascer, independentemente de querer ou não.

\section{REFERÊNCIAS}

CANDIDO, A. Textos de intervenção. São Paulo: Duas Cidades/Ed. 34, 2002.

GARCIA, O. M. Esfinge clara e outros enigmas. Rio de Janeiro: Topbooks, 1996.

MELLO, E. C. O nome e o sangue. Rio de Janeiro: Topbooks, 2000.

MELO NETO, J. C. Obra completa. Rio de Janeiro: Nova Aguilar, 1994.

Obra completa. Rio de Janeiro: Nova Aguilar, 2008.

SECCHIN, A. C. Poesia e desordem. Rio de Janeiro: Topbooks, 1996.

VASCONCELOS, S. João Cabral de Melo Neto: retrato falado do poeta. Recife: Ed. do Autor, 2009.

Artigo recebido em 01/09/2012 Aceito para publicação em 24/09/2012 